\title{
Старожилов В.T.
}

\section{Моделирование ландшафтов водосборов Сихотэ-Алинской области как основы мониторинга и моделирования состояния водных объектов суши}

Дальневосточный федеральный университет

(Россия, Владивосток)

doi: $10.18411 / \mathrm{j}-09-2020-34$

idsp: ljournal-09-2020-34

\section{Аннотация}

Рассматриваются на примере равнинного и горного типа ландшафтов высотноландшафтные комплексы Сихотэ-Алинской области как звена Тихоокеанского ландшафтного пояса России. Выделяются равнинные, мелкосопочные, низкогорные, расчлененносреднегорные, массивносреднегорные, гольцовые высотно-ландшафтные комплексы. Структурирование и классификация представляются для дальнейшего изучения структур, как объектов отраслевой индикации и как основы мониторинга и моделирования состояния водных объектов суши в том числе качества воды и возможностей использования высотно-ландшафтных комплексов, как территорий освоения.

Ключевые слова. Ландшафт, высотно-ландшафтный комплекс, водосбор, освоение.

Введение. Предлагаемое читателю структурирование и классификация ландшафтов водосборов представляются как основы для дальнейшего изучения структур как объектов отраслевой индикации, мониторинга и моделирования состояния водных объектов суши в том числе качества воды и возможностей использования высотно-ландшафтных комплексов, как территорий освоения и изучения водной экологии региона.

Работа представляет собой продолжение исследований Тихоокеанского международного ландшафтного центра ШЕН ДВФУ, в целом сформировавшейся ландшафтной школы ДВФУ и разработанных парадигм: общей Дальневосточной ландшафтной парадигмы и Дальневосточной ландшафтной парадигмы индикации и планирования [1] (doi:10.18411/1j-05-2020-26), разработок по картографическому оцифрованному ландшафтному обеспечению индикации, планирования и геоэкологического мониторинга юга Тихоокеанского ландшафтного пояса России (doi:10.18411/lj-05-2020-27)[2]. Рассматривается структурирование Сихотэ-Алинской области как звена Тихоокеанского ландшафтного пояса, который представляет собой азональный пояс ландшафтной сферы с генетически единым структурнотектоническим положением в зоне окраинно-континентальной дихотомии системы океан-континент и характеризуется аккреционной природой фундамента ландшафтных сихотэалинской, нижнеамурской, приохотской, сахалинской, камчатско-курильской, чукотской и др. географических областей (структур) с климатическим и растительным внутренним содержанием, подчиняющимся высотной и широтной зональности и эволюционирующим под действием взаимодействующих, взаимосвязанных и взаимопроникающих друг в друга орогенического, орографического, климатического и фиторастительного факторов. (рис.1) 


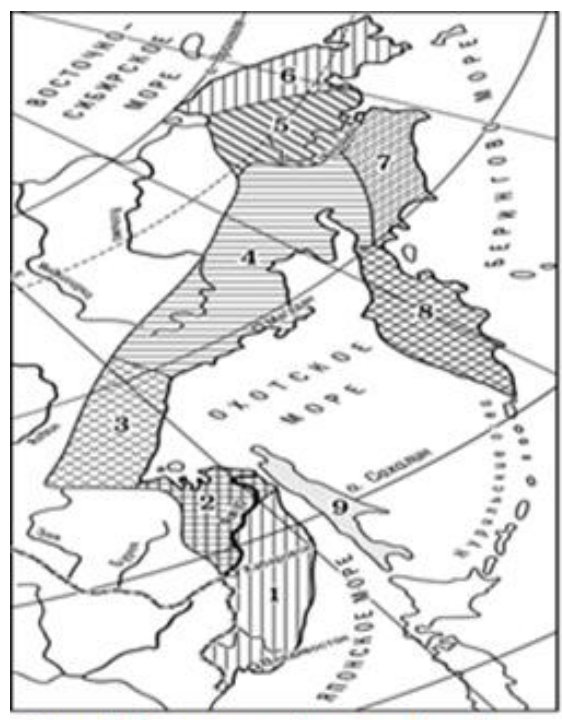

Pис. 1. Тнхоокеавский ландшафтный пояс России (Старожилов, 2013).

Области пояса: 1. Сихот9-Алинская,

2. Никн еамурская; 3.Приох от ская;

4. Кольмскан; 5. Анадырьская;

6. पухотская; 7.Корякская,

8. Камчатско-Курильская,

9. Сахалинсвая

Предлагается на примере Сихотэ-Алинской системы, для тихоокеанских горных территорий, проводить структурирование и классификацию ландшафтных территорий с выделением высотно-ландшафтных комплексов с изучением вертикальной и горизонтальной дифференциации как универсального свойства количественного и качественного изменения внутреннего содержания высотно - ландшафтных систем и использования полученных материалов для мониторинга и моделирования состояния водных объектов суши. При этом под высотно-ландшафтным комплексом понимаются генетически связанные ассоциации ландшафтов, определяемые рельефом, общим генетическим и динамическим, подчиняющимся законам причинно-следственных связей, состоянием эрозионно-денудационных систем, функционирующих под действием вещественно-энергетических потоков Земли и в первую очередь гравитационной энергии.

Структурирование и классификация проводились в различных масштабах на планетарном, среднемасштабном и локальном уровнях. В статье рассматривается структурирование на среднемасштабном уровне. При выделении среднемасштабных высотно-ландшафтных комплексов доминантными являются высотный критерий и количественные и качественные изменения их внутреннего содержания с учетом состояния эрозионно-денудационных систем, функционирующих под действием вещественно-энергетических потоков Земли и в первую очередь гравитационной энергии.

По этим критериям ландшафтные территории классифицируются и выделяются равнинные, мелкосопочные, низкогорные, расчлененносреднегорные, массивносреднегорные, гольцовые высотно-ландшафтные комплексы. Структурирование и классификация представляются для дальнейшего изучения структур, как объектов отраслевой индикации и возможностей использования высотноландшафтных комплексов, как объектов освоения.

Отмеченное, а также то, что исследование проведено впервые и нацелено на практическую реализацию ландшафтного подхода в освоении территорий, определяет актуальность выполненной работы. 
Материалы. Рассматриваются материалы результатов научных и практических исследований в сфере геолого-географического изучения и ландшафтного картографирования Сихотэ-Алинской системы как звена Тихоокеанского ландшафтного пояса России (рис.1). Изучались материалы соотношений и взаимосвязи достаточно значимых данных не только по рельефу, растительности и почвам, но и коренным и рыхлым породам, климату [3-9] .

В статье приводятся материалы результатов, полученных на основе авторских полевых (более 30 полевых сезонов автора) и производственных по практической реализации ландшафтного метода в различных областях природопользования: в области туризма и рекреации, градостроительства, лесопользовании, планирования и проектирования природопользования и др. [10-14].

Использовались результаты картографирования отдельных областей Тихоокеанского ландшафтного пояса, например, ландшафтная классификация, базовая ландшафтная карта Приморского края М 1: 500000 и легенда к ней, разработанная в масштабе 1: 500000 ландшафтная классификация Сахалинской области [15], продолжающихся ландшафтных исследований по другим территориям Тихоокеанской России и в том числе острове Русском; особенности формирования фундамента ландшафтов Тихоокеанского ландшафтного пояса на основе авторской концепции его акреционной геодинамической эволюции, с опорой на изучение петрографического состава и структурно-тектоническое положение осадочных и других литокомплексов [16].

При выделении и классификации высотно-ландшафтных комплексов использовались материалы ландшафтной индикации.

Выше отмечено только часть использованных материалов. В них ранее рассмотрены отдельные вопросы при выполнении задач по разным разделам ландшафтоведения. Общего их анализа как основы концепции высотно-ландшафтных комплексов и их классификации ранее не проводилось. В связи с этим, все они, в том числе и авторские полевые (30 полевых сезонов), нами использованы как основы для решения задачи структурирования и классификации высотно-ландшафтных комплексов.

Результаты. В целом на основе анализа, синтеза и оценке значимого полевого и теоретического материала установлен фундаментальный результат настоящих исследований, заключающийся в том, что для реализации концепции структурирования высотно-ландшафтных структур как природных основ ведения гармонизированных с природой отраслевого освоения территорий необходимо иметь прежде всего оцифрованную векторно-слоевую морфологическую ландшафтную основу [3].

В результате исследований разработана классификация и выделяются высотноландшафтные комплексы. Они разные и разделяются на равнинные, мелкосопочные, низкогорные, расчлененносреднегорные, массивносреднегорные, гольцовые комплексы.

Равнинный высотно-ландшафтный комплекс в границах находит отчетливое отражение на морфологических ландшафтных картах и занимает ландшафтное равнинное пространство, например, в Приморском крае, занимает ландшафтное равнинное пространство Уссури-Ханкайской ландшафтной провинции. Включает равнинную территорию дальневосточного равнинного класса ландшафтов с характерным для нее сочетанием лесостепного равнинного и долинно-речного подкласса и равнинного эрозионно-аккумулятивного и долинно-речного и приморскоравнинного родов.

Низкогорный высотно-ландмафтный комплекс. Это горы с абсолютными отметками 300-800 м и относительными превышениями до 200-250 м. Для них характерны прямые, реже выпуклые, склоны, покрытые мощным слоем щебнистых суглинков, мощность которых у подножий гор обычно увеличивается. Обнажения 
отмечаются редко. Это обычно либо денудационные останцы и гребни, сложенные устойчивыми к выветриванию горными породами на вершинах и склонах, либо эрозионные (абразионные) обрывы у подножий гор.

Низкогорный высотно-ландшафтный комплекс характеризуется сложной дифференцированностью ландшафтных растительных и почвенных группировок. Среди растительных преобладают широколиственные леса, а в почвенных - бурые-лесные. Комплекс характеризуются замедленным боковым выносом мелкозема в процессе суффозии и бокового почвенного смыва, преобладающим термокриповым и гигрокриповым транзитом склоновых отложений, с заметным обогащением верхних слоев разреза грубообломочным материалом при сохранении их преимущественно суглинистого состава. Широко распространены явления промежуточной склоновой аккумуляции на перегибах и у подножьев склона. Территории относятся к участкам с замедленной денудацией и активной аллювиальной и склоновой аккумуляцией.

Включает горную территорию дальневосточного горного класса ландшафтов с ландшафтами доминантного горно - смешанно-широколиственного, редкого горнотемнохвойного подклассов, доминантного низкогорного полисубстратного и терригенного родов. Для комплекса доминантный - низкогорный пихтово-елово-лиственичномелколиственный вид горно- смешанно-широколиственного пояса и включает комплекс пихтово-еловых, лиственничных, елово-лиственичных и мелколиственных лесов (местами с широколиственными породами) на горно-таежных бурых и др. почвах. Имеет быстрый водообмен на узких водоразделах и крутых склонах, слабо сдержанный на широких водоразделах и выположенных склонах. Встречается пихтово-елово-лиственичномелколиственный вид горно - смешанно-широколиственного пояса и включают комплекс пихтово-еловых, лиственничных, елово-лиственичных и мелколиственных лесов (местами с широколиственными породами) на горно-таежных бурых и др. почвах. Имеет быстрый водообмен.

Расчлененносреднегорный высотно-ландшафтный комплекс. Включает горную территорию дальневосточного горного класса ландшафтов с ландшафтами доминантного горно - смешанно-широколиственного, горно-темнохвойного подклассов, доминантного полисубстратного и терригенного родов. Это горы с абсолютными отметками более 800 м. Развит на территории с глубоким расчленением первоначально единых массивов на большое число узких извилистых хребтов и обособленных вершин с глубоко расчлененными склонами. Это территории с резко очерченными водораздельными гребнями, очень крутыми прямыми или выпуклыми в верхней части склонами, к которым на япономорском макросклоне приурочены подвижные осыпи, часто покрывающие склоны от подножья до вершины. Из растительных группировок преобладают кедровошироколиственные и елово-пихтовые леса. На склонах, поросших древесной растительностью, развиты щебнистые и щебнисто-дресвяные суглинки, служащие минеральной основой преобладающих бурых и желто-бурых почв. Вверх по склону обычно отмечается увеличение количества грубообломочного материала, обогащение им верхней части склоновых накоплений, увеличивается крупность обломочного материала. В целом этот комплекс ландшафтов относится к области активной денудации, но существенную роль играют также процессы аллювиального транзита и промежуточной аккумуляции. Кроме того, для высотного расчлененносреднегорного комплекса ландшафта характерно: заметное преобладание продуктов физического выветривания в общем объеме мобилизованного материала зоны разрушения скальных пород; широкое распространение обвально-осыпных явлений и осовов; эпизодическое проявление курумового транзита, солифлюкции и морозного выпучивания; каньонообразные формы эрозионного врезания вершин водотоков, значительные продольные уклоны долин в зоне руслового водного транзита обломочного материала.

Массивносреднегорный высотно-ландшафтный комплекс. Включает горную территорию дальневосточного горного класса ландшафтов с ландшафтами доминантного 
горно - смешанно-широколиственного, горно-темнохвойного подклассов, доминантного полисубстратного и терригенного родов. Это горы с абсолютными отметками более 800 м. Характеризуется преобладанием наиболее возвышенных куполовидных массивов и линейно вытянутых горных кряжей, обычно контролируемых выходами на поверхность наиболее устойчивых к выветриванию горных пород, представленных молодыми интрузиями, экструзиями, метосамотическими полями, купольными, ядерными и диапировыми структурами. Распространены вершины округлых очертаний и уплощенные широкие водораздельные перегибы. Это районы таежных группировок хвойных лесов с преобладанием ели аянской и пихты белокорой в хвойной и березы - в лиственной составляющих. Верхнюю границу леса формируют подгольцовые ельники, отличающиеся мощным развитием травянистого покрова и кустарничкового яруса. Преобладающими почвами являются горно-таежные бурые иллювиально-гумусовые, формирующиеся в условиях быстрого водообмена. Растительность формируется на глыбово-дресвянощебнистой коре выветривания с относительно высоким содержанием суглинка в разрезе. В целом это области активной денудации и локальной аккумуляции. Кроме того, для массивносреднегорного высотно-ландшафтного комплекса характерно: значительное преобладание продуктов физического выветривания в общем объеме мобилизованного обломочного материала зоны разрушения скальных горных пород; заметное проявление курумового транзита, осовов, солифлюкции, морозного выпучивания и обвально-осыпных явлений; циркообразные формы глубинной эрозии в водосборной зоне и большие продольные уклоны долин в зоне руслового водного транзита обломочного материала.

Гольцовый высотно-ландмафтный комплекс. Включает горную территорию дальневосточного горного класса ландшафтов с ландшафтами доминантного горнотундрового подкласса, доминантного полисубстратного и терригенного родов. Распространен на гольцовых, подгольцово-горных, каменистых россыпях, осыпях, курумах и каменистых потоках, приуроченных к гребням водоразделов, вершинам и склонам гор, развит не широко. В большинстве случаев это самые возвышенные участки гор, округлые вершины и террасированные склоны. На северном Сихотэ-Алине ландшафты этого комплекса довольно часто отмечаются с отметок 700 - 900м. Характеризуются маломощным чехлом обломочных накоплений, малым количеством мелкозема в их разрезе, слаборазвитыми фрагментарными каменистыми почвами. В таких условиях глубина промерзания значительно превышает мощность слоя рыхлых накоплений, что приводит к интенсивному развитию явлений отторжения обломков скальных пород и выпучивания их вверх вплоть до дневной поверхности. Этому способствуют продолжительные резкие перепады суточных температур осенью и весной, высокий уровень солнечной радиации, переувлажнение грунтов.

Почвы горно-тундровые в гольцовом и иллювиально-гумусовые и дерновоорганические в подгольцовом поясах. Горные тундры характеризуются преобладанием в покрове кустистых лишайников (особенно ягелей). Встречаются одиночные кусты низкорослого кедрового стланика. В зоне подгольцовых частей гор развиты стелющиеся леса кедрового стланика. К местам скопления каменисто-глыбовых отложений склонов всех экспозиций приурочены лишайники.

В целом для гольцового высотно-ландшафтного комплекса характерно: интенсивное проявление и широкое распространение процессов вершинного выравнивания и гольцовой планации; активное морозно-мерзлотное, химическое и биологическое выветривание с образованием грубообломочного структурного элювия; активный вынос мелкозема в процессе суффозии, солифлюкции и бокового подпочвенного смыва; интенсивное проявление курумового, термокрипового и криокрипового транзита грубообломочного материала; формирование осовов (камнепадов) на склонах и как следствие быстрое смещение склоновых накоплений на значительные расстояния (вплоть до подножия склонов); широкое распространение явлений солифлюкции и морозного выпучивания. 
Заключение. Подводя итоги, констатируем, что в сложившейся Ландшафтной школе Дальневосточного федерального университета разработана и сформирована под руководством профессора В.Т. Старожилова научно-практическое направление структурирования ландшафтов Сихотэ-Алинской системы. Констатируется выделение равнинных, мелкосопочных, низкогорных, расчлененносреднегорных, массивносреднегорных, гольцовых высотно-ландшафтных комплексов. Все они сопровождаются составлением полимасштабных морфологических, индикационных и других векторно-слоевых ландшафтных карт. В целом сложилось важное направление для создания платформы для разработки планов и проектов развития территорий. Она также является платформой для обучения студентов открываемой магистратуры по программе «Ландшафтное планирование». Представляет собой часть основ фундаментального научно-прикладного направления, разработанного в Тихоокеанском международном ландшафтном центре ДВФУ и направленного на рациональное освоение и использование территорий.

Изучение комплексов важно не только с точки зрения разработок научных основ ландшафтоведения, но и как направление исследований стратегических возможностей применения знаний о них при комплексном и отраслевом освоении ландшафтного пространства, мониторинга, моделирования и прогнозирования состояния водных объектов, качества воды и изучения водной экологии регионов. В настоящее время Тихоокеанский международный ландшафтный центр ДВФУ продолжает разрабатывать концептуальную методологию оцифрованного структурирования горных территорий азональных ландшафтных поясов (водосборов) и возможности использования этих материалов при освоении территории Тихоокеанской России. Географы ДВФУ уже подготовили базовую ландшафтную карту Приморского края в масштабе 1:500 000, ландшафтную карту Русского острова в масштабе 1:25 000, ландшафтную классификацию Сахалинской области, продолжают исследования по другим регионам Тихоокеанского ландшафтного пояса России.

$$
* * *
$$

1. Старожилов В.Т. Дальневосточная ландшафтная парадигма индикации и планирования // Тенденции развития науки и образования. №61.Часть 2. Изд. НИЦ. «Л-Журнал».2020. - 28-36с

2. Старожилов В.Т. Картографическое оцифрованное ландшафтное обеспечение индикации, планирования и геоэкологического мониторинга юга Тихоокеанского ландшафтного пояса России // Тенденции развития науки и образования. №61.Часть 2. Изд. НИЦ. «Л-Журнал».2020. -36-42c

3. Старожилов В.Т. Природопользование: практическая ландшафтная география. / учебник. Школа естественных наук ДВФУ, Тихоокеанского международного ландшафтного центра, Школа естественных наук ДВФУ. Владивосток, 2018. 2765с

4. Старожилов В.Т. Атлас Приморского края. Вострецов Ю.Е., Кононенко Н.А., Сергеев О.И., Тураев В.А., Галлямова Л.И., Мандрик А.Т., Проскурина Л.И., Ващук А.С., Медведева Л.М., Иванов В.В., Тащи С.М., Крылов И.И., Ларенцева С.И., Зонова И.Г., Яковлева Л.М., За На.Юн., Ознобихин В.И., Розенберг В.А., Краснопеев С.М., Кудрявцева Е.П. и др.Владивосток, 2008.

5. Старожилов В.Т. Почвы ландшафтов Приморья (рабочая классификация). Костенков Н.М., Нестерова О.В., Пуртова Л.Н., Крупская Л.Т., Дербенцева А.М., Назаркина А.В., Пилипушка В.Н., Семаль В.А., Старожилов В.Т. учебное пособие для студентов высших учебных заведений, обучающихся по направлению высшего профессионального образования 20700 "Почвоведение" / Владивосток, 2011.

6. Старожилов В.Т. Эколого-ландшафтный подход в формировании региональной экологической политики на территории стран АТЭС / В сборнике: Шестые Гродековские чтения. Актуальные проблемы исследования Российской цивилизации на Дальнем Востоке. межрегиональная научнопрактическая конференция. Правительство Хабаровского края. Хабаровск, 2009. С. 24-28.

7. Старожилов В.Т. Региональные компоненты и факторы структуры и пространственной организации ландшафтов юга Дальнего Востока (на примере Приморского края). - Москва, 2008.

8. Старожилов В.Т. Статистический анализ прстранственного распределения ландшафтов окраинноконтинентальных геосистем Тихоокеанской России // Эколого-геоморфологические исследования в урбанизированных и техногенных ландшафтах (Арчиковские чтения - 2015). ФГБОУ ВПО «Чувашский государственный университет имени И.Н. Ульянова. -2015. -С. 102-113. 
9. Старожилов В.Т. Ландшафтное картографирование территорий Приморского края // Известия Российской академии наук. Серия географическая. -2010. -№ 2. -С. 82-89.

10. Старожилов В.Т., Зонов Ю.Б. Ландшафтные предпосылки устойчивого развития территорий. / В сборнике: Природа без границ. Материалы I Международного экономического форума. Администрация Приморского края. 2006. С. 261-265.

11. Старожилов В.Т., Дербенцева А. М., Евсеев А. Б., Ткаченко В. И., Степанова А. И. Процессы механической деградации почв в ландшафтах Приморья: моногр. - Владвосток : Изд-во Дальневост. ун-та, 2009. - 86 с.

12. Старожилов В.Т., Дербенцева А. М., Крупская Л. Т., Евсеев А. Б Техногенные изменения ландшафтов, обусловленные промышленным производством в Приморском крае // Экологические систᄀлемы и приборы. - 2009. - № 6. - С. 52-55

13. Старожилов В.Т. Эколого-ландшафтный подход к промышленным территориям юга Дальнего Востока // В сборнике: Современные геофизические и географические исследования на Дальнем Востоке России. материалы 9-й научной конференции, Владивосток: конференция приурочена к Всемирным дням воды и метеорологии, а также к 110-летию ДВГУ и 45-летию ГФФ. Дальневосточный государственный университет, Институт окружающей среды ; под редакцией Н. В. Шестакова. Владивосток, 2010. С. 155-158.

14. Старожилов В.Т. Проблемы ресурсопользования, структура и пространственная организация ландшафтов приокеанских Дальневосточных территорий // В сборнике: Науки о Земле и отечественное образование: история и современность. материалы Всероссийской научнопрактической конференции, посвященной памяти академика PАО А. В. Даринского. Российский государственный педагогический университет им. А. И. Герцена, факультет географии. 2007. С. 310-312.

15. Старожилов В. Т. Ландшафтные геосистемы Сахалинского звена Тихоокеанской России // В сборнике: Научная дискуссия: гуманитарные, естественные науки и технический прогресс. Материалы VII Всероссийской научно-практической конференции. 2015. С. 54-64.

16. Старожилов В.Т. Ноосферные проблемы, структура и пространственная организация ландшафтов дальневосточных территорий (на примере Приморского края) // Материалы Международной научно-практической конференции «Ноосферные изменения в почвенном покрове». Дальневосточный государственный университет. -2007. -С. 31-37.

\title{
Старожилов В.T. \\ Парадигма направлений картографического моделирования ландшафтов как природного «фундамента» освоения территорий
}

\author{
Дальневосточный федеральный университет
}

(Россия, Владивосток)

doi: $10.18411 / \mathrm{j}-09-2020-35$

idsp: ljournal-09-2020-35

\section{Аннотация}

В статье констатируется, что в России в Ландшафтной школе Дальневосточного федерального университета разработана и сформирована под руководством профессора В.Т. Старожилова актуальная научно-практическая парадигма по фундаментальным направлениям картографического моделирования ландшафтов как природного «фундамента» освоения территорий. Она направлена на рациональное освоение и использование территорий, минимизацию глобальных и региональных последствий изменения природы и общества и поиск и внедрение инновационных подходов в устойчивом, экологически сбалансированном и безопасном развитии региона. Отмечается, что парадигма - одна из разработанной в Тихоокеанском международном ландшафтном центре ШЕН ДВФУ общей Дальневосточной ландшафтной парадигмы и Дальневосточной ландшафтной парадигмы индикации и планирования (doi:10.18411/1j-05-2020-26)[1] . Она основана на синтезе, анализе и оценке материалов по экологии и ландшафтоведению. Базируется на использовании результатов векторно-слоевого картографирования, ландшафтной и экологической индикации внутреннего содержания территорий освоения Дана информация об обеспеченности Тихоокеанской России современными цифровыми ландшафтными основами и документами для решения поставленных задач по её освоению и развитию, 